\title{
DESARROLLO DE UN QUESO MADURO \\ CON ADICIÓN DEL CULTIVO PROBIÓTICO \\ LACTOBACILLUS PARACASEI SUBSP. PARACASEI LC-01
}

\author{
DEVELOPMENT OF MATURE CHEESE \\ WITH THE ADITTION OF THE PROBIOTIC CULTURE \\ LACTOBACILLUS PARACASEI SUBSP. PARACASEI LC-01
}

\author{
Esteban Boza M., Ileana Morales H., Marjorie Henderson G. \\ Centro Nacional de Ciencia y Tecnología de Alimentos. \\ Universidad de Costa Rica. San José, Costa Rica.
}

\begin{abstract}
The probiotic culture Lactobacillus paracasei subsp. paracasei LC-01 was incorporated to a mature cheese in order to obtain a functional product for a minimal reasonable period before its consumption. The ideal period of maturation for the cheese was determined by evaluating with consumers the acceptability of the flavor and texture of samples after 13.30 and 45 days of maturation to $12{ }^{\circ} \mathrm{C}$ and $85 \% \mathrm{RH}$. The process of cheese elaboration was modified by pressing with a number of viable probiotic cells up to $1 \times 106 \mathrm{UFC}$. A significant increment $(\alpha=5 \%)$ was detected in the re-counts of Lactobacillus paracasei subsp. paracasei for the three studied times of maturation. The $p H$ value of the product fell throughout the 45 days of maturation. There weren't significant differences $(\alpha=5 \%)$ in the flavor and texture acceptability of the cheeses put under different times of maturation. The probiotic population stayed stable (1x $107 \mathrm{UFC} / \mathrm{g}$ average) for a 15 days maturated cheese, throughout 45 days of storage at $5^{\circ} \mathrm{C}$. Key words: mature cheese; probiotics; maturation: functional meal; survival.
\end{abstract}

Este trabajo fue recibido el 15 de Enero de 2009, aceptado con modificaciones el 27 de Abril de 2009 y aceptado para ser publicado el 10 de Mayo de 2010.

\section{INTRODUCCIÓN}

El estilo de vida de hoy en día, sumado a los efectos secundarios de las terapias con antibióticos, ha hecho que las personas prefieran enfoques preventivos para su salud para evitar posibles padecimientos (1). Esta situación ha provocado un aumento considerable de la demanda de nuevos alimentos funcionales como lo son los probióticos. A pesar que el consumo de probióticos data desde mucho tiempo, la conciencia pública acerca de sus beneficios ha aumentado considerablemente en los últimos años. La demanda del mercado costarricense e internacional ha impulsado una nueva línea de alimentos funcionales probióticos, tales como quesos, leches fermentadas, helados, entre otros (2).

La FAO define los probióticos como: "microorganismos vivos que ejercen una acción benéfica sobre la salud del huésped al ser administrados en cantidades adecuadas" (3). Los alimentos probióticos poseen niveles importantes de estas bacterias las cuales producen una serie de componentes biológicamente activos que ofrecen efectos fisiológicos deseables más allá de sus efectos nutricionales (4).

Según Rasic (5), para que un individuo obtenga efectos beneficiosos al ingerir estas bacterias se requiere un número muy alto de células viables (108-109/ día). Esta dosis diaria puede ser alcanzada si se consume como mínimo $100 \mathrm{~g}$ de producto con bacterias probióticas viables y disponibles en una concentración aproximadamente de $106 \mathrm{ufc} / \mathrm{g}$ de producto (6). Sin embargo algunos autores recomiendan que el producto contenga 108ufc/g de bacterias probióticas para compensar la posible reducción de las mismas en su paso por el tracto 
gastrointestinal (7).

De manera convencional, los alimentos utilizados para llevar al consumidor los beneficios de los probióticos han sido las leches fermentadas, ya que reúnen una serie de factores que las hacen aptas para tal fin. Sin embargo, el queso podría ser un mejor vehículo para estos microorganismos que los alimentos tradicionalmente empleados, por tener una mayor capacidad amortiguadora, mayor exclusión del oxígeno y mayor contenido graso, lo que favorecería la resistencia y supervivencia de los microorganismos durante el almacenamiento y el tránsito intestinal $(8,9)$.

La cepa LC-01, resiste la acidez gástrica, y puede llegar viable al intestino del consumidor (10). Se ha observado que tiene un fuerte efecto antioxidante contra la peroxidación del ácido linoleico (11). Además, ha mostrado buena adhesión a las células de la pared celular, e induce la producción de citoquinas, por parte de los leucocitos (12). El LC-01, también ha mostrado ser un estimulante del sistema inmune, al favorecer la producción de citoquina, en el combate de una necrosis Alpha. En un estudio (13), se observó que esta cepa fue la más estable, entre las cepas de Lactobacillus acidophilus (LA-5) y Bifidobacterium bifidus (BB-12) en el suero reconstituido fermentado (14).

Con el fin de obtener un producto que pueda ser considerado funcional por un período mínimo razonable para su consumo, se planteó como objetivo desarrollar una tecnología de elaboración de queso maduro inoculado con Lactobacillus paracasei subesp. paracasei determinando un período ideal de maduración para el queso, evaluando con consumidores la aceptabilidad del sabor y la textura de productos sometidos a distintos tiempos de maduración, así como evaluando la sobrevivencia del microorganismo probiótico a lo largo del tiempo de almacenamiento.

\section{METODOLOGÍA \\ Elaboración del queso}

El queso se elaboró en la Planta Piloto del Centro Nacional de Ciencia y Tecnología de Alimentos, de la Universidad de Costa Rica. Fue producido a partir de 53,0 L de leche (finca Pasquí, S.A., Cartago, Costa Rica) descremada por gravedad $(4 \% \mathrm{~m} / \mathrm{v}$ grasa, $3,6 \% \mathrm{~m} / \mathrm{v}$ proteína) y pasteurizada $\left(63^{\circ} \mathrm{C}\right.$ x $30 \mathrm{~min}$. $)$, empleando el cultivo iniciador mixto $\mathrm{CHN}-11$ (Lactococcus lactis subsp. cremoris, Lactococcus lactis subsp. lactis, Leuconostoc mesenteroides subsp. cremoris y Lactococcus lactis subsp. diacetylactis) de la casa CHR-Hansen (Alfa, S.A., San José, Costa Rica).

Luego de pasteurizada, la leche fue atemperada a 35 ${ }^{\circ} \mathrm{C}$ antes de la adición del cultivo iniciador $(75 \mathrm{U} / 500 \mathrm{~L}$ leche), por inoculación directa (DVS), en una concentración de $0,05 \%(\mathrm{~m} / \mathrm{m})$, cloruro de calcio (Laboratorios VacoS.A., San José, Costa Rica, 50 ml/100 L leche) y nitrato de potasio (Vaco, $40 \mathrm{ml} / 40 \mathrm{~L}$ leche). La leche se dejó reposar 5 min se le agregó renina comercial Vaco (20 ml/40 L leche) y después de un período de $40 \mathrm{~min}$ la cuajada se cortó para producir cubos de aproximadamente $1,5 \mathrm{~cm}$ de arista, fue cocida a $38-40{ }^{\circ} \mathrm{C}$ durante 30 min con agitación lenta después de un desuerado parcial. Posteriormente se separó el resto del suero y se formaron bloques de cuajada que se dejaron reposar por una hora, con un volteo a los $30 \mathrm{~min}$. Seguidamente se colocó la cuajada en moldes de acero inoxidable de 1-2 Kg y se realizó un pre-prensado a $1,38 \times 10^{5} \mathrm{~Pa}$ por $10 \mathrm{~min}$. A continuación se desmoldó la cuajada y se desmenuzó mecánicamente en una marmita Stephan para queso fundido.

Se procedió a adicionar el cultivo probiótico Lactobacillus paracasei subsp. paracasei LC-01 de CHR-Hansen en una mezcla seca con sal común, en una concentración tal que permitió obtener niveles del probiótico superiores a $1 \times 10^{7} \mathrm{UFC} / \mathrm{g}$. La cuajada se volvió a colocar en los moldes y se prensó a 2,76 x $10^{5}$ Pa durante 16 horas. Luego del prensado, los quesos se cortaron en piezas de aproximadamente $400 \mathrm{~g}$ utilizando una cobertura para maduración de acetato de polivinilo (PVA) y se colocaron sobre bandejas plásticas en una cámara a $12^{\circ} \mathrm{C}$ y $85 \%$ HR para su maduración con volteo cada 2 a 3 días.

\section{Estudio durante la maduración}

En un ensayo escalonado se elaboraron 4 lotes de queso por periodo de maduración. Cada lote de queso estuvo compuesto por cuatro piezas individuales rectangulares de aproximadamente $400 \mathrm{~g}$. Cada lote de queso se maduró por períodos de $0,13,30$ y 45 días, de manera que al final de los 45 días se contó con los quesos correspondientes a los tres tiempos de maduración y al control (0 días de maduración) para realizar los recuentos del Lactobacillus paracasei subsp. paracasei, medición de $\mathrm{pH}$ del producto y la evaluación con consumidores para analizar su sabor y textura.

Los recuentos por esparcimiento en placa del microorganismo Lactobacillus paracasei subsp. paracasei se realizaron siguiendo la guía de la casa Chr-Hansen (10) que incluye el método para el recuento de bacterias probióticas, esto con el fin de garantizar que el queso mantenía un nivel aceptable de UFC probióticas para funcionalidad durante la maduración. Como medio de cultivo se empleó Agar MRS con glucosa. Se pesaron 25 $\mathrm{g}$ de queso por muestra y se prepararon las correspondientes diluciones decimales en agua peptonada estéril 
$(0,1 \% \mathrm{v} / \mathrm{v})$. Las diluciones apropiadas se sembraron por duplicado. Las placas se incubaron en aerobiosis durante 6 días, a una temperatura de $23^{\circ} \mathrm{C}$, según indicaciones de la guía. Las colonias de Lactobacillus paracasei subsp. paracasei fueron blancas, mientras que las procedentes del cultivo CHN-11, amarillentas. También se picaron diversas colonias de cada color y se realizaron tinciones simples para corroborar la diferencia morfológica entre las bacterias.

Para determinar el pH se usó el método descrito por Segura (4). Para cada tiempo de muestreo se pesaron por triplicado $10 \mathrm{~g}$ de cada repetición del queso y se mezclaron con $10 \mathrm{~mL}$ de agua destilada. Se homogenizó y se midió el pH. Se usó un medidor digital de $\mathrm{pH}$ Metrohm 827.

\section{Evaluación de la aceptabilidad con consumidores}

Se realizó una prueba de aceptación con consumidores para establecer un periodo pertinente de maduración para el queso que se analizó en el estudio de almacenamiento en refrigeración (sección 2.4). Se evaluó la aceptabilidad del sabor y la textura del queso sometido a los distintos períodos de maduración (13, 30 y 45 días), con 75 consumidores de queso maduro. Tres muestras rectangulares de aproximadamente $5 \mathrm{~g}$ de queso a temperatura ambiente $\left(20-23^{\circ} \mathrm{C}\right)$ correspondientes a los distintos tiempos de maduración fueron presentadas aleatoriamente a los consumidores para su evaluación. Se empleó una escala hedónica lineal de $10 \mathrm{~cm}$, rotulada en los extremos (me disgusta mucho o me gusta mucho) y a la mitad (me es indiferente) (15).

\section{Estudio durante el almacenamiento en refrigeración}

Se elaboraron 4 lotes de queso y cada uno compuesto por nueve piezas individuales rectangulares. Estos quesos se maduraron durante 15 días. Luego se empacaron al vacío y se almacenaron en refrigeración $\left(3^{\circ} \mathrm{C}\right.$ a $\left.7^{\circ} \mathrm{C}\right)$ para su estudio a lo largo de 49 días. Los análisis realizados fueron la medición de $\mathrm{pH}$ y recuento del microorganismo probiótico. Los tiempos de muestreo fueron: $0,7,14,21,28,35,42$ y 49 días.

\section{Análisis estadístico}

Para el estudio de maduración (secciones 2.2 y 2.3) se empleó un diseño experimental con un arreglo irrestricto aleatorio con tres tratamientos (tiempos de maduración). Para la medición de $\mathrm{pH}$ se hicieron dos repeticiones, y para el recuento del probiótico, cuatro repeticiones. Los datos obtenidos para los ensayos de aceptación, recuento del probiótico y medición de $\mathrm{pH}$ se analizaron mediante un análisis de variancia y una prueba de comparación de medias de Tukey, con un nivel de significancia $(\alpha)$ del $5 \%$.

Para el análisis del producto durante la refrigeración se realizaron cuatro repeticiones del experimento. Con los resultados de los recuentos del probiótico y los valores de $\mathrm{pH}$ a lo largo del almacenamiento se llevaron a cabo las correspondientes regresiones lineales en función del tiempo, utilizando el paquete estadístico JMP. Se calcularon los límites de confianza usando un $\alpha$ de $5 \%$.

\section{RESULTADOS}

Viabilidad del $L$. paracasei durante la maduración y el almacenamiento en refrigeración

En la figura 1a se muestra la viabilidad del probiótico empleado en el experimento, el recuento aumenta significativamente $(\mathrm{p}<0,05)$ a través del tiempo de maduración durante el período evaluado. En el cuadro 1 se presentan los resultados del análisis de variancia para el recuento del probiótico durante distintos tiempos de maduración.

Durante el presente estudio se encontró un comportamiento estacionario del probiótico durante el almacenamiento en refrigeración, sin haber una tendencia de descenso o crecimiento significativa (figura $1 b$ ).

En la figura 2a se muestra los valores de $\mathrm{pH}$ del queso probiótico durante distintos tiempos de maduración. Hay una disminución significativa $(\mathrm{p}<0,05)$ en el pH del

\section{CUADRO 1}

\section{Análisis de variancia para el recuento del probiótico durante distintos tiempos de maduración}

\begin{tabular}{lccccc}
\hline Fuente de variación & gl & Suma de cuadrados & Cuadrado medio & Valor de F & Prob > F \\
\hline tiempo de maduración (días) & 3 & 3,6310250 & 1,21034 & 51,3673 & $<.0001$ \\
Error & 12 & 0,2827500 & 0,02356 & & \\
C. total & 15 & 3,9137750 & & &
\end{tabular}


queso a lo largo del tiempo de maduración, debido a la producción de ácidos orgánicos (16).

Del mismo modo, como se aprecia en la figura $2 b$, se encontró una tendencia significativa $(p<0,05)$ en el descenso del $\mathrm{pH}$ durante el almacenamiento en refrigeración del queso madurado por 15 días.

Análisis sensorial de la aceptabilidad del producto

En las figuras $3 \mathrm{a}$ y $3 \mathrm{~b}$ se representan los resultados de la aceptabilidad promedio de la textura y el sabor de muestras de queso sometidas a los distintos períodos de maduración.

\section{DISCUSIÓN}

Viabilidad del $L$. paracasei durante la maduración y el almacenamiento en refrigeración

Aunque se reconoce que la tendencia general en quesos ha sido que los cultivos probióticos mantienen o pierden la viabilidad durante el almacenamiento o la maduración, existen ejemplos de especies probió-

\section{FIGURA 1-a}

Logaritmo del número de unidades formadoras de colonia de Lactobacillus paracasei subsp paracasei por g de queso para distintos tiempos de maduración a $12^{\circ} \mathrm{C}$ y $85 \% \mathrm{HR}$.

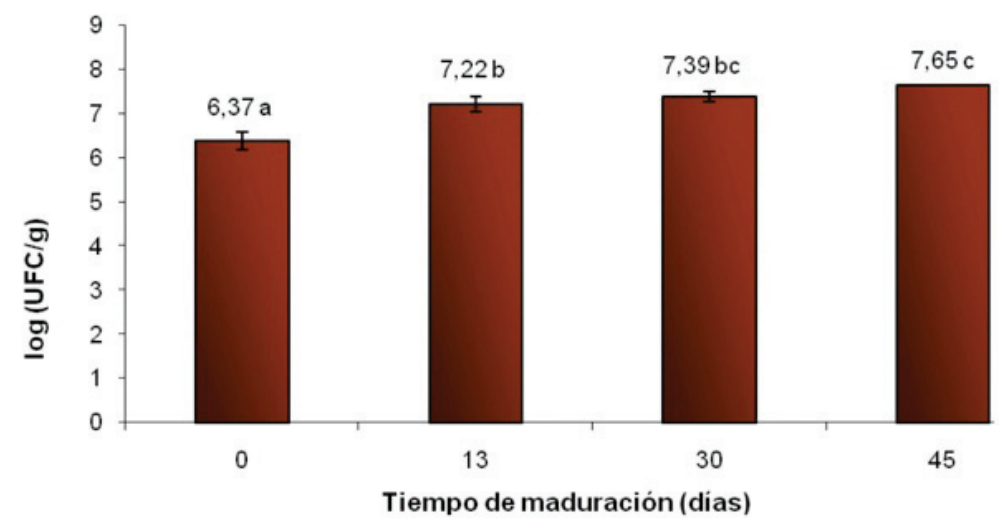

\section{FIGURA 1-b}

Logaritmo del número de unidades formadoras de colonia de Lactobacillus paracasei subsp paracasei por $\mathrm{g}$ de queso durante 49 días de almacenamiento al vacío del producto a $5^{\circ} \mathrm{C}$

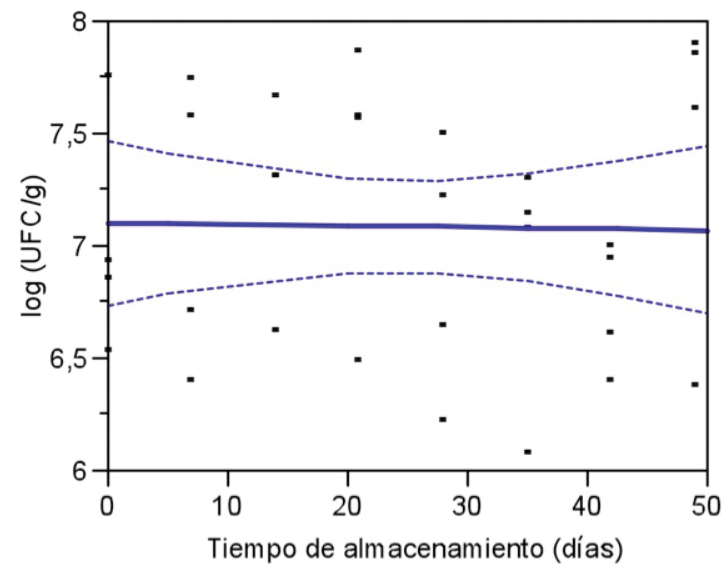




\section{CUADRO 2}

Análisis de variancia para el pH durante distintos tiempos de maduración

\begin{tabular}{|lccccc|}
\hline Fuente de variación & gl & Suma de cuadrados & Cuadrado medio & Valor de F & Prob > F \\
\hline tiempo de maduración (días) & 3 & 3,4382458 & 1,14608 & 428,8426 & $<.0001$ \\
Error & 20 & 0,0534500 & 0,00267 & & \\
C. total & 23 & 3,4916958 & & & \\
\hline
\end{tabular}

\section{FIGURA 2-a}

Mediciones de pH para el queso incorporado con Lactobacillus paracasei subsp paracasei y madurado por distintos períodos a $12^{\circ} \mathrm{C}$ y $85 \% \mathrm{HR}$.

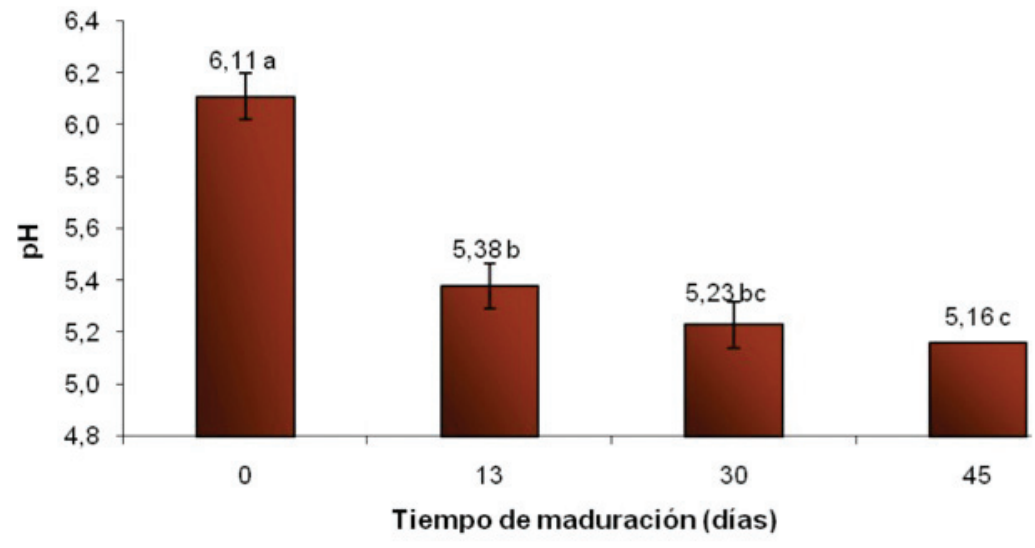

\section{FIGURA 2-b}

Mediciones de pH para el queso incorporado con Lactobacillus paracasei subsp paracasei madurado por 15 días y almacenado al vacío por 49 días a $5^{\circ} \mathrm{C}$.

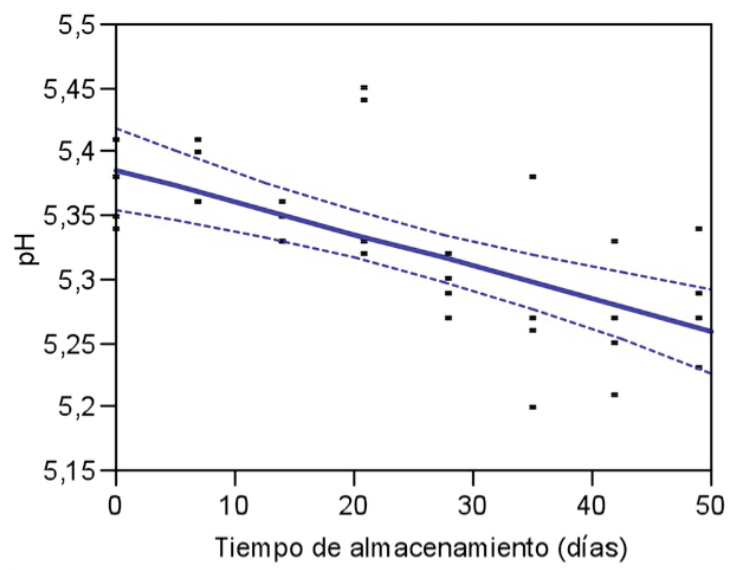




\section{CUADRO 3}

Análisis de variancia para el agrado del sabor a distintos tiempos de maduración

Fuente de variación gl Suma de Cuadrados Cuadrado Medio Valor de F Prob $>$ F

tiempo de maduración (días)

Error

2

25,5086

12,7543

1,7979

0,1680

C. total

\section{FIGURA 3-a}

Aceptabilidad sensorial promedio del sabor para el queso incorporado con Lactobacillus paracasei subsp paracasei y madurado por distintos tiempos a $12^{\circ} \mathrm{C}$ y $85 \% \mathrm{HR}$.

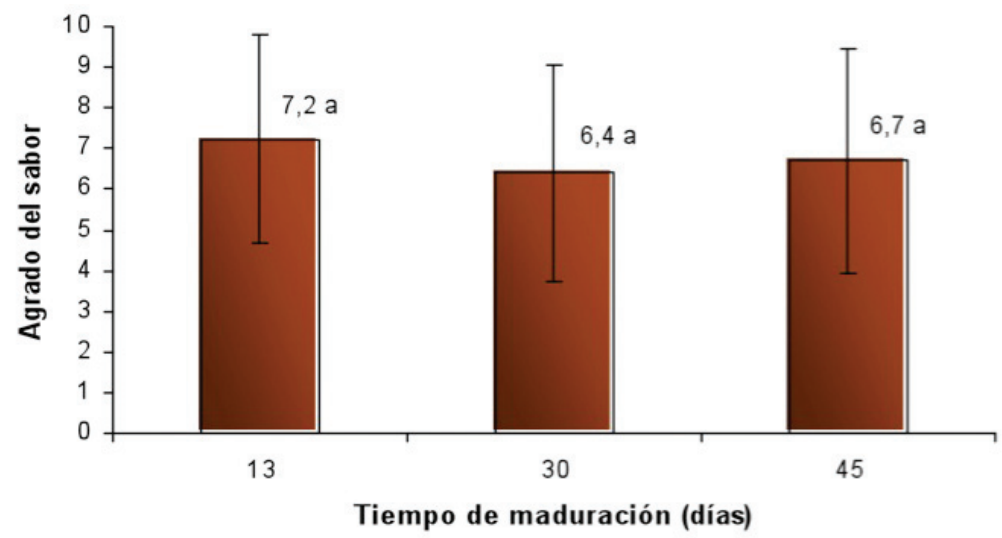

\section{FIGURA 3-b}

Aceptabilidad sensorial promedio de la textura para el queso incorporado con Lactobacillus paracasei subsp paracasei y madurado por distintos tiempos a $12^{\circ} \mathrm{C}$ y $85 \% \mathrm{HR}$.

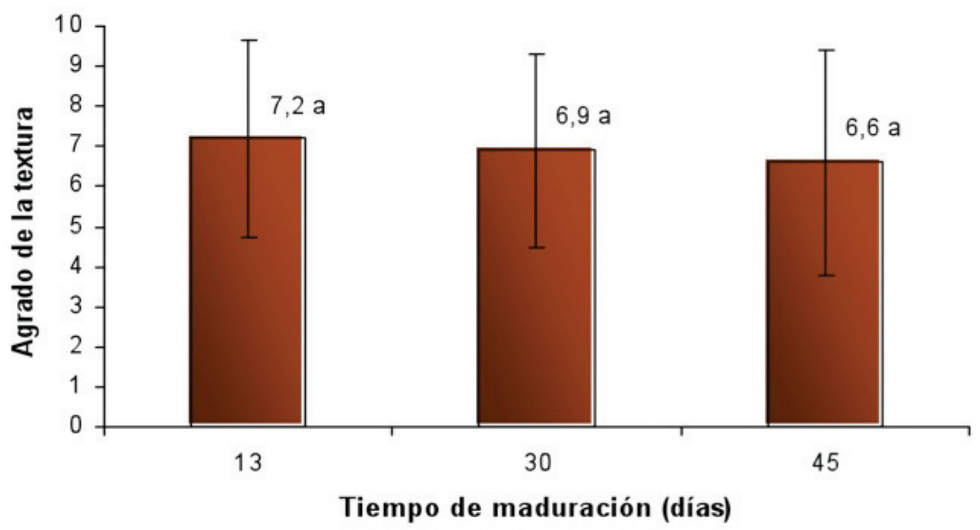


ticas que eventualmente han logrado crecer durante el almacenamiento (17). Gardiner y colaboradores (9), emplearon una cepa de Lactobacillus paracasei como cultivo probiótico en queso Cheddar. Los autores encontraron un incremento en la población del probiótico de $1,7 \times 105 \mathrm{UFC} / \mathrm{mL}$ hasta $2,9 \times 10^{8} \mathrm{UFC} / \mathrm{mL}$ durante los primeros 3 meses de maduración a $8^{\circ} \mathrm{C}$, después de lo cual el recuento del probiótico se mantuvo estable. No obstante, el crecimiento del L. paracasei durante la maduración podría deberse a la cepa empleada, la microflora acompañante y/o la temperatura de maduración. En otra investigación se empleó este microorganismo como probiótico (en mezcla con L acidophilus y B. lactis) en queso Cheddar madurado a $4^{\circ} \mathrm{C}$, el comportamiento de dicho probiótico fue estacionario durante los 6 meses de maduración (18).

En la presente investigación se utilizó una temperatura de maduración aún mayor a la empleada por Gardiner y colaboradores (13), $12{ }^{\circ} \mathrm{C}$ en promedio, lo que posiblemente favoreció el crecimiento de la cepa probiótica utilizada, el Lactobacillus paracasei subsp paracasei se ha aislado naturalmente de quesos madurados y reconocido como flora no iniciadora (19), lo que indica que la matriz del queso resulta un buen sustrato para el crecimiento de esta bacteria, posiblemente por presentar una cantidad importante de nutrientes y un $\mathrm{pH}$ adecuado para su crecimiento.

Se ha señalado al $\mathrm{pH}$ como un factor crítico para la sobrevivencia de las bacterias probióticas (20); sin embargo, la sensibilidad a la acidez es un fenómeno que varia entre especies e incluso entre cepas de una misma especie, y se reconoce a $L$. casei como relativamente resistente comparado con L. acidophilus o las bifidobacterias (17). Para este caso particular está claro que el descenso en el $\mathrm{pH}$ del producto no afectó negativamente la viabilidad del cultivo probiótico, permaneciendo esta última por encima del nivel recomendado para obtener un producto funcional a lo largo de la maduración.

\section{Análisis sensorial de la aceptabilidad del producto}

Se esperaba que estas pruebas con consumidores permitieran establecer el tiempo óptimo de maduración en el que el queso presentaría las características de mayor agrado. No obstante, para este caso no se encontraron diferencias significativas $(\mathrm{p}>0,05)$ ni en el sabor ni en la textura de las muestras analizadas, lo que dificultó la definición de un tiempo ideal de maduración. Ivankovich y Aguilar (21) señalan que muchas personas que dicen consumir quesos madurados en Costa Rica prefieren productos de un sabor no muy fuerte (8-22 días de maduración), pues la tendencia ha sido la de consumir el queso lo más fresco posible. Por esta razón, se decidió madurar el queso en el primer tiempo en que no se encontraron diferencias con el tiempo cero, aproximadamente a los 13 días.

\section{CONCLUSIONES}

Se logró adecuar eficazmente la formulación y el proceso para lograr niveles superiores a 1 x $10^{6} \mathrm{UFC} / \mathrm{g}$ del probiótico Lactobacillus paracasei. subsp. paracasei en el queso recién prensado, lo que hace que éste cumpla con los estándares establecidos para los alimentos funcionales probióticos en cuanto al número de unidades formadoras de colonia. Con los resultados de los recuentos del microorganismo probiótico obtenidos en este estudio para los distintos tiempos de maduración y durante el almacenamiento en refrigeración, se demuestra que el queso madurado constituye una buena matriz para mantener niveles adecuados de esta bacteria. Por otra parte, no se encontraron diferencias significativas $(\alpha=5 \%)$ en la aceptabilidad del sabor y la textura para los quesos sometidos a los distintos tiempos de maduración utilizados en el ensayo, por lo que no fue posible la selección de un tiempo ideal de maduración basándose en esta metodología.

Estos resultados permiten al sector lácteo del país y de la región, contar con una metodología para la elaboración de un queso maduro con características funcionales.

\section{RESUMEN}

A un queso maduro se le incorporó el cultivo probiótico Lactobacillus paracasei subsp. paracasei LC-

\section{CUADRO 4}

Análisis de variancia para el agrado de la textura a distintos tiempos de maduración

\begin{tabular}{lccccc} 
Fuente de variación & gl & Suma de cuadrados & Cuadrado medio & Valor de $\mathbf{F}$ & Prob > F \\
\hline tiempo de maduración (días) & 2 & 14,7512 & 7,37560 & 1,1179 & 0,3288 \\
Error & 222 & 1464,6864 & 6,59769 & & \\
C. total & 224 & 1479,4376 & & &
\end{tabular}


01 para obtener un producto funcional por un período mínimo razonable para su consumo. Se determinó un período ideal de maduración para el queso evaluando con consumidores la aceptabilidad del sabor y la textura de muestras de 13,30 y 45 días de maduración a $12{ }^{\circ} \mathrm{C}$ y $85 \%$ HR. Se modificó el proceso de elaboración del queso para obtener un queso recién prensado con un número de células probióticas viables mayor a 1 x 106 UFC. Se encontró un incremento significativo $(\alpha=5 \%)$ en los recuentos del Lactobacillus paracasei subsp. paracasei para los tres tiempos de maduración estudiados con respecto al queso recién prensado. Los valores de $\mathrm{pH}$ del producto disminuyeron a través de los 45 días de maduración. No se hallaron diferencias significativas $(\alpha=5 \%)$ en la aceptabilidad del sabor y la textura para los quesos sometidos a los distintos tiempos de maduración. La población del probiótico se mantuvo estable (1x 107 $\mathrm{UFC} / \mathrm{g}$ en promedio) para un queso madurado 15 días, a lo largo de 49 días de almacenamiento a $5^{\circ} \mathrm{C}$, sin que se haya registrado una tendencia de descenso o crecimiento significativa $(\alpha=5 \%)$.

Palabras clave: Queso maduro; probióticos; maduración; alimento funcional; sobrevivencia.

Dirigir la correspondencia a:

Profesor

Esteban Boza M.

Centro Nacional de Ciencia y

Tecnología de Alimentos.

Universidad de Costa Rica

Código postal: 2060

San José,

Costa Rica

Teléfono: (506) 25-11-34-31

Fax: (5م6) 22-53-37-62 / (506) 22-24-97-25

Email:cita@ucraccr

Página Web: www.cita.ucr.ac.cn

\section{BIBLIOGRAFIA}

1. Talwaker, A. Kailasapathy, K. A review of oxygen toxicity in probiotic yogurts: Influence on the survival of probiotic bacteria and protective techniques, Comprensive Rev Food Sc Food Safety 2004; 3:117-123.

2. Taranto, M. Medici, M. Font, G. Alimentos funcionales probjóticos Tucumán, Argentina 2005 INTERNET wwy.quimicaviva.qb.fcen.uba.ar v4n1/alimprob.pdf

3. Boza, E. Desarrollo de queso maduro adicionado con el cultivo prebiótico Lactobacillus paracasei subs. Paracasei Lc-01. Tesis Lic. en Tecnología de Alimentos. Universidad de Costa Rica, Escuela de
Tecnología de Alimentos, San José, 2008.

4. Segura, N. Elaboración de queso fresco tipo Turrilaba con probióticos. Tesis Lic. en Tecnología de Alimentos. Universidad de Costa Rica, Escuela de Tecnología de Alimentos, San José, 2005.

5. Rasic, J. The role of dairy foods containing bifidoand acidophilus bacteria in nutrition and health. North European Dairy J 1983. 4:1-10.

6. Shah,N. Functional foods from probiotics and prebiotics. Food Technol 2001. 55 (10):36-42.

7. Corriols, M. Determinación de la sobrevivencia del (Bifidobacterium lactis) en una natilla liviana durante el período de almacenamiento. Tesis Lic. en Tecnología de Alimentos. Universidad de Costa Rica, Escuela de Tecnología de Alimentos, San José, 2004.

8. Delgado, C. Castro, M. Elqueso y los probióticos S 12004 INTERNET www.tecnologiadelqueso. com/conocer/72003.php

9. Drgalic, I, Tratnik, Bozanic, 2005. Growth and Survival of probiotic bacteria in reconstituted whey, Zagreb. Lait 85. 2005. 171-179.

10. CHR-HANSEN. L. acidophilus, L. casei and Bifidobacteria in fermented milk products Guidelines In Method for counting probiotic bacteria. Technical Bulletin, F6. s.1. 2005.

11. Kim, H. Chae, H. Jeong, S. Ham, J. Im, S. Ahn, C. Lee, J. Antioxidanr activity of some yogurt starter cultura. Asian-Austral. J Animal Sci 2004. 18(2):255-258.

12. Salminen, S. Isolauri, E. Salminen, E. Clinical uses of probiotics for stabilizing the gut mucosal barrier: successful strains and the future challenges. Antonie Van Leeuwenhoek. 1996. 70:347-358.

13. Gardiner, G. Roos, P. Collins, J. Fitzgerald, G. Stanton, C. Development of a probiotic Cheddar cheese containing human-derived Lactobacillus paracasei strains, Applied Environ Microbiol 1998; 64 (6): 2192-2199.

14. Gutiérrez, E. Desarrollo de una bebida de suero dulce derivado de la fabricación de queso fresco, fermentada con cultivos Lactobacillus helveticus y Sterptococcus salivarius var termophilus (TCC-20), adicionada con cultivos prebióticos Lactobacillus paracasei subsp. paracasei LC-01. Tesis Lic. en Tecnología de Alimentos. Universidad de Costa Rica, Escuela de Tecnología de Alimentos, San José, 2005.

15. ISO-4121:2003,Sensory analysis - Guidelines for the use of quantitative response scales

16. Belitz, H.D. Grosch, W. Química de los Alimentos. Editorial ACRIBIA, Zaragoza, 1992. 
17. Champagne, C. Gardner, N. Challenges in the addition of probiotic cultures to foods, Critical Rev Food Sci Nutr 2005; 45: 61-84.

18. Ong, L. Henrikkson, A. Sha, N. Development of probiotic Cheddar cheese containing L. acidophilus, L. casei, L. paracasei and Bifidobacterium sp. and the influence of these bacteria in proteolytic patterns and organic acid production. Internat Dairy J 2006; 16: 446-456.

19. Lynch, C. M. Muir, D. Banks, J. McSweeney, P.L.
Fox, P. Influence of adjunct cultures of Lactobacillus paracasei ssp. paracasei or Lactobacillus plantarum on Cheddar cheese ripening. J Dairy Sci 1999; 82: 1618-1628.

20. Roy, D. Technological aspects related to the use of bifidobacteria in dairy products, Lait $2005 ; 85$ : 39-56.

21. Ivankovich, C. Aguilar, F. Generalidades sobre las motivaciones asociadas al consumo de queso. CITA, San José, 1989. 